\title{
Experimental Study for Evaluating Structural Behavior of RC Beams Strengthened by Different Width of FRP Layers
}

\author{
Naeun Kim, Young-Hee Kim, and Hee Sun Kim
}

\begin{abstract}
This paper reports experimental studies of reinforced concrete (RC) beams strengthened by carbon fiber reinforced polymer sheet (CFRPs) having different width. The objective of this study is to evaluate effect of different width of CFRPs on structural behaviors of $\mathrm{RC}$ beams and investigate most effective height of CFRPs on the side surfaces of RC beams for flexural strengthening. Toward this goal, five $\mathrm{RC}$ beams are fabricated and strengthened with different width of CFRPs, and then four-point bending tests with the simply supported beams are performed. Results of this study show that the width of strengthened CFRPs on RC beams has a significant influence on structural behaviors of RC beams.
\end{abstract}

Index Term-CFRPs, CFRP width, RC beams, strengthening effect

\section{INTRODUCTION}

Fiber reinforced polymer (FRP) is widely used for reinforcing structural members due to its high strength, light weight, and simple installation. For evaluating strengthening effect of FRP, many studies have been performed using experimental and analytical methods [1]-[10]. Because early debonding of FRP sheet (FRPs) from structural members is one of the significant factors to determine strengthening effect of FRPs, previously reported studies have suggested methods to delay early debonding using anchorage system or proper configuration of FRPs [11]. About configurations of FRPs, length, thickness, and width of CFRPs have been reported as influencing parameters on structural behaviors of RC beams [12]-[14]. Among them, experimental study about width of CFRPs shows that CFRPs is able to delay debonding failure of RC beams that is similar to case of using anchorage system in RC beams strengthened with FRPs [15]. In addition, effect of CFRPs width on structural behaviors of RC beams is investigated by Brena and Macri [16]. In their experiments, it is seen that load capacity of beam increases with CFRPs width.

In this study, an effect of width of CFRPs on structural behavior of RC beams is investigated. Four-point bending tests are performed using RC beams strengthened with two layers of CFRPs, which variables are width of CFRPs. For the experiment, width of the CFRPs are same as or wider than beam width in order to investigate strengthening effect

Manuscript received April 7, 2013; revised June 1, 2013. This work was supported by National Research Foundation of Korea (NRF-2011-0008824)

The authors are with the Department of Architectural Engineering, master course, Ewha Womans University, 52, Ewhayeodae-gil, Seodaemun-gu, Seoul 120-750, Korea (e-mail: bambi_kim@nate.com, kawaee02@hotmail.com,hskim3@ewha.ac.kr). according to covered area of beam side surfaces by CFRPs To analyze strengthening effect, maximum load, load-deflection curves, stress distributions of CFRPs, ductility and failure modes are examined from the experiments.

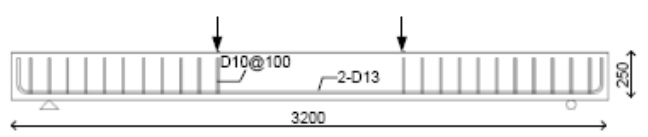

(a) CONT

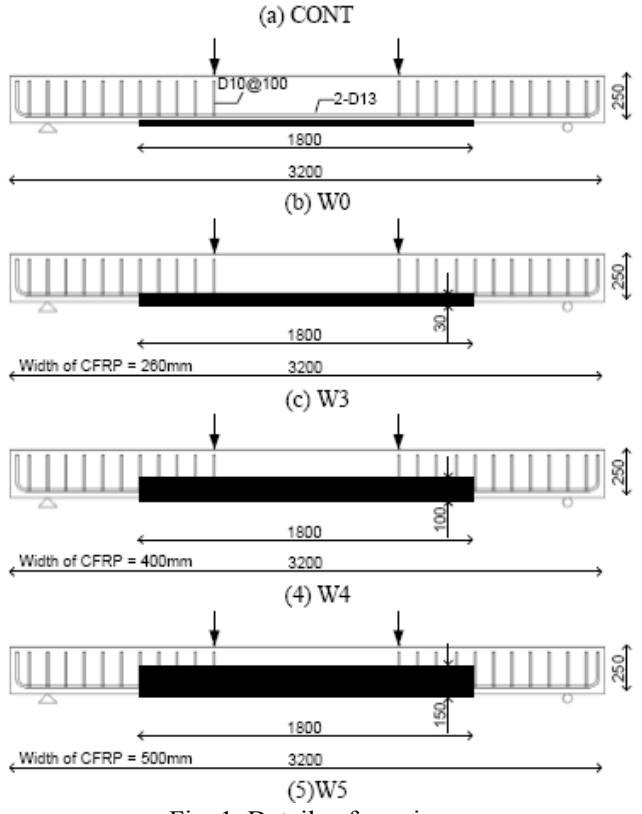

Fig. 1. Details of specimens

\section{EXPERIMENTAL PROGRAM}

\section{A. Details of Tested Beams}

Notation and variables of specimens are listed in Table I. Five RC beams are fabricated with dimensions of $200 \mathrm{~mm} \times$ $250 \mathrm{~mm} \times 3200 \mathrm{~mm}$ (width $\times$ depth $\times$ length), and all beams are internally reinforced with reinforcing steel bars of $13 \mathrm{~mm}$ diameter at an effective depth $203.5 \mathrm{~mm}$, as illustrated in Figs. 1. Also, all beams are reinforced with stirrups of $10 \mathrm{~mm}$ diameter for preventing beams from being governed by shear failure prior to flexural failure. CFRPs are externally attached on the bottom surface of RC beams. Length of CFRPs and numbers of CFRPs layers are same for all specimens, but widths of CFRPs are $200 \mathrm{~mm}, 260 \mathrm{~mm}, 400 \mathrm{~mm}$, and $500 \mathrm{~mm}$ for W0, W3, W4, and W5 specimens, respectively. CONT specimen denotes a control beam, which is not strengthened with CFRPs. Attaching CFRPs is conducted after curing for 21 days by professional technicians. Surfaces of RC beams to 
attach CFRPs are sanded, primer and top-coat are applied in orders, followed by impregnating CFRPs with epoxy. The impregnated CFRPs are attached to the bottom surfaces of $\mathrm{RC}$ beams such that direction of CFRPs is same as longitudinal direction of RC beams.

TABLE I: LIST OF SPECIMENS

\begin{tabular}{cccc}
\hline \hline Specimen & $\begin{array}{c}\text { CFRPs width } \\
(\mathrm{mm})\end{array}$ & $\begin{array}{c}\text { CFRPs length } \\
(\mathrm{mm})\end{array}$ & $\begin{array}{c}\text { Number of } \\
\text { layers }\end{array}$ \\
\hline W0 & 200 & 1800 & 2 \\
W3 & 260 & 1800 & 2 \\
W4 & 400 & 1800 & 2 \\
W5 & 500 & 1800 & 2 \\
CONT & & No CFRPs & \\
\hline \hline
\end{tabular}

\section{B. Material Properties}

Mixing proportion is based on Table II for fabricating regular strength concrete, and compressive strength is obtained as $29 \mathrm{MPa}$ from compressive test after curing for 28 days in room temperature. Also, tensile strength of concrete is measured as $3 \mathrm{MPa}$ from material tests.

Material properties of CFRP, primer, and top-coat are provided from manufacturer as listed in Table III.

\section{Instrumentation and Testing}

RC beams strengthened with CFRPs are simply supported for performing four point bending test as shown in Fig. 2. After beam is placed, load is applied as displacement control until beam failure.

During tests, vertical deflections of RC beams are measured at bottom surface of mid span using linear variable displacement transfer (LVDT). To measure strain of concrete, electric strain gages are attached upper and side surface. The strains of rebar and FRP are measured in longitudinal span using electrical strain gages as shown in Fig. 3.

TABLE II: MIXING PROPORTIONS FOR CONCRETE

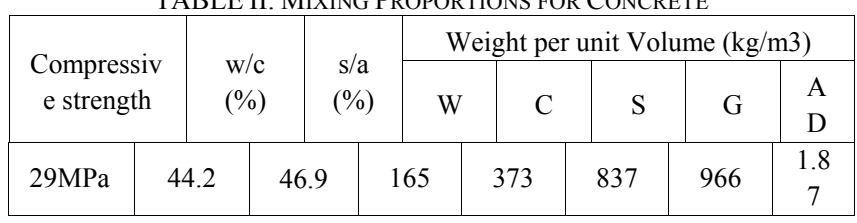

TABLE III: MATERIAL PROPERTIES OF CFRPS AND ADHESIVES

\begin{tabular}{|c|c|c|c|c|}
\hline \multirow{2}{*}{ Type } & $\begin{array}{c}\text { Thickness } \\
(\mathrm{mm})\end{array}$ & $\begin{array}{c}\text { Elastic } \\
\text { modulus } \\
(\mathrm{GPa})\end{array}$ & $\begin{array}{c}\text { Tensile } \\
\text { strength } \\
(\mathrm{GPa})\end{array}$ & $\begin{array}{c}\text { Flexural } \\
\text { strength } \\
(\mathrm{MPa})\end{array}$ \\
\hline CFRP & 0.5 & 245.2 & 4.5 & - \\
Primer & 3.2 & 2.46 & 0.055 & 82.4 \\
Top-coat & 3.2 & 3.11 & 0.063 & 99.3 \\
\hline
\end{tabular}

\section{RESULTS}

\section{A. Load-Deflection Relationships}

Load-deflection curves of all specimens are illustrated in Fig. 4. As shown in Fig. 4, maximum loads of specimens strengthened with CFRPs generally increase as width of CFRPs increases. Exceptionally, W3 specimen results lower maximum load than W0, which width of CFRPs for W0 is narrower than CFRPs for W3. Therefore, it is interesting to note that strengthening effect of attaching CFRPs up to side surfaces of RC beam can be improved depending on the CFRPs area covering beams.

Also, stiffness of RC beams strengthened with CFRPs increases with CFRP width. For RC beams strengthened with CFRPs wider than beam width (W3, W4, and W5), deflection at beam failure are smaller than deflection of $\mathrm{W} 0$ at beam failure. Among W3, W4, and W5, deflection at beam failure increase with width of CFRPs.

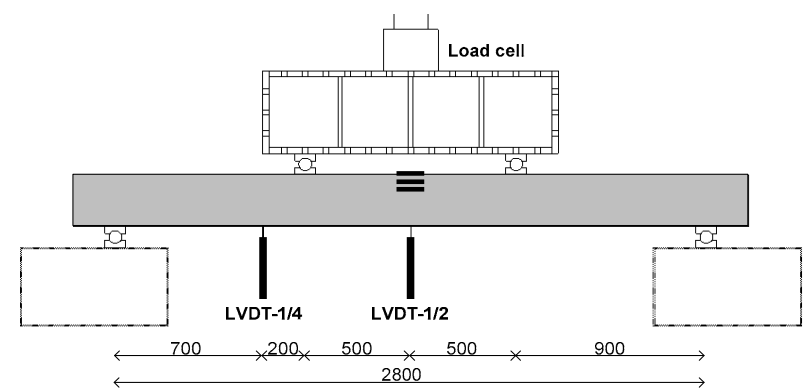

Fig. 2. Test set-up and Instrumentation

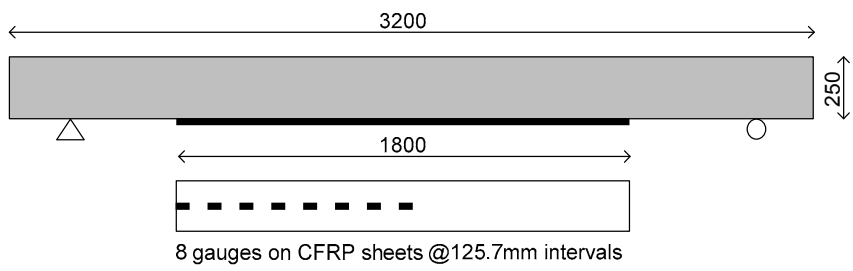

Fig. 3. Location of CFRP strain gages

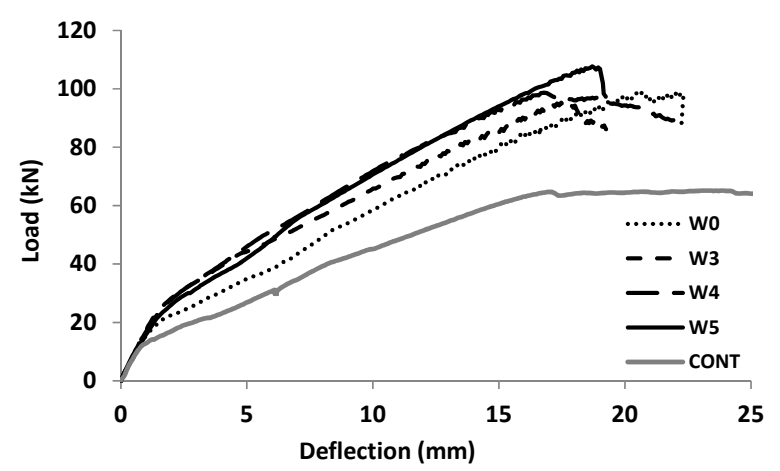

Fig. 4. Load-deflection relationships

\section{B. Interfacial Stress Distributions}

Interfacial shear stress, $\tau$, is one of the important factors for analyzing structural behaviors, since it determines beam failure by initiating debonding of CFRPs. Therefore, interfacial shear stresses are calculated using (1), where, $t_{p}$ and $E_{P}$ are thickness and elastic modulus of CFRPs, respectively. Strains of CFRPs are measured using gages attached on CFRPs with intervals of $125 \mathrm{~mm}$ in longitudinal direction and used to calculate interfacial shear stresses.

$$
\tau=t_{P} E_{P} \frac{d \varepsilon}{d x}
$$

Interfacial shear stress between CFRPs layers and bottom surfaces of concrete is illustrated in Fig. 5. For most specimens, maximum interfacial shear stresses occur at the end of CFRPs layers, where debonding of CFRPs is initiated. W5 specinmens show largest interfacial shear stress at the end of CFRPs compared to all the specimens, while W0 shows the smallest. Also, maximum interfacial shear stress is not observed at the end of CFRPs for W0, may be because 
debonding is initiated from the end of CFRPs when measured at $95 \%$ of maximum load level.

TABLE IV: EXPERIMENTAL RESULTS

\begin{tabular}{cccccc}
\hline \hline Specimen & $\begin{array}{c}\text { Load at } \\
\text { failure } \\
(\mathrm{kN})\end{array}$ & $\begin{array}{c}\text { Mid-span } \\
\text { deflection at } \\
\text { failure } \\
(\mathrm{mm})\end{array}$ & $\begin{array}{c}\text { Steel } \\
\text { strain } \\
\text { at failure } \\
\left(10^{-3}\right)\end{array}$ & $\begin{array}{c}\text { CFRP strain } \\
\text { at failure } \\
\left(10^{-3}\right)\end{array}$ & $\begin{array}{c}\text { Concrete } \\
\text { strain } \\
\text { at failure } \\
\left(10^{-3}\right)\end{array}$ \\
\hline W0 & 99 & 22 & 2.135 & 2.337 & -1.136 \\
W3 & 95 & 18 & 3.045 & 3.441 & -1.402 \\
W4 & 99 & 17 & 2.590 & 2.992 & -1.351 \\
W5 & 108 & 19 & 3.151 & 3.456 & -1.331 \\
CONT. & 69 & 76 & 7.119 & - & -1.219 \\
\hline \hline
\end{tabular}

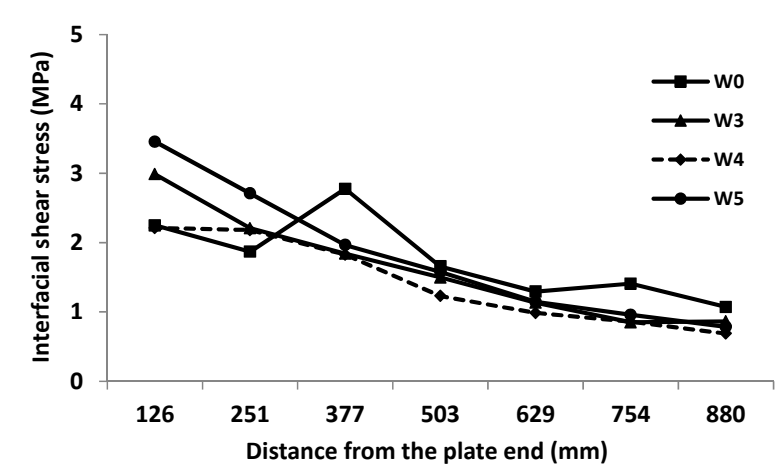

Fig. 5. Interfacial shear stress measured at $95 \%$ of maximum load level

\section{Ductility}

It is important to examine ductility, since RC beams strengthened with CFRPs often show brittle behaviors and sudden failures unexpectedly. In this study, deflection ductility $\left(\mu_{D}\right)$ and energy ductility $\left(\mu_{E}\right)$ are calculated based on yield of reinforcing steel bars using (2) and (3), and listed in Table $\mathrm{V}$.

$\mu_{D}=$ (midspan deflection at maximum load) $/($ midspan deflection at tension steel yield)

$\mu_{E}=$ (area of load-deflection curve up to maximum load)/ (area of load-deflection curve at tension steel yield)

For RC beams strengthened with wider CFRPs than beam width (W3, W4, and W5), ductility increases with CFRPs width. However, ductility for W3, W4, and W5 are smaller compared to ductility of W0 and CONT. These results mean that CFRPs covering side surfaces of RC beams contributes to resist against loads even after yielding of reinforcing steel bars for W3, W4, and W5.

\section{Failure Modes}

Failure modes and crack propagations of all the tested specimens are observed as illustrated in Figs. 6(a)-(e). As shown in Fig. 6(a), CONT specimen shows flexural cracks and failure in compressive zone. From strain gauges attached to reinforcing steel bars of CONT specimen, it is seen that reinforcing steel bars yield prior to failure in concrete compressive zone. RC beams strengthened with CFRPs shows sudden failure due to debonding of CFRPs. At beam failure, CFRP layers and part of concrete covers are separated from RC beams, initiated from one end of CFRP layers. Also, CFRPs inW5 specimen show debonding without concrete cover separation, because stresses are distributed throughout wide area of CFRPs covering side surfaces of RC beams. Since CFRP layers cover both compressive and tensile zone of concrete side surfaces in W5 specimen, debonding of CFRP is induced from combined mechanism of compressive and tensile stresses developed on side surfaces of RC beams.

\begin{tabular}{|c|c|c|c|c|}
\hline \multirow{2}{*}{ specimens } & \multicolumn{2}{|c|}{ Deflection ductility } & \multicolumn{2}{c|}{ Energy ductility } \\
\cline { 2 - 5 } & $\mu_{D}$ & $\begin{array}{c}\text { Ratio to } \\
\text { CONT. }\end{array}$ & $\mu_{E}$ & $\begin{array}{c}\text { Ratio to } \\
\text { CONT. }\end{array}$ \\
\hline CONT & 4.98 & 1.0 & 8.16 & 1.0 \\
\hline W0 & 2.43 & 0.49 & 2.98 & 0.37 \\
\hline W3 & 1.41 & 0.28 & 1.77 & 0.22 \\
\hline W4 & 1.42 & 0.29 & 1.76 & 0.22 \\
\hline W5 & 1.59 & 0.32 & 2.17 & 0.27 \\
\hline
\end{tabular}

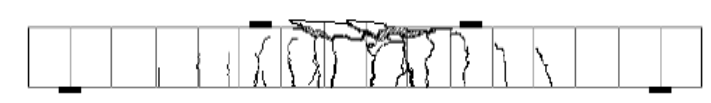

(a) CONT

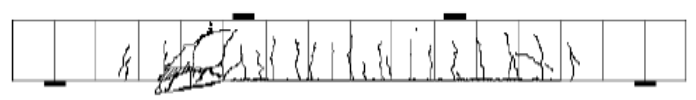

(b) W0

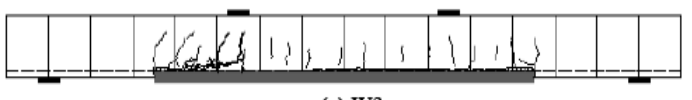

(c) W3

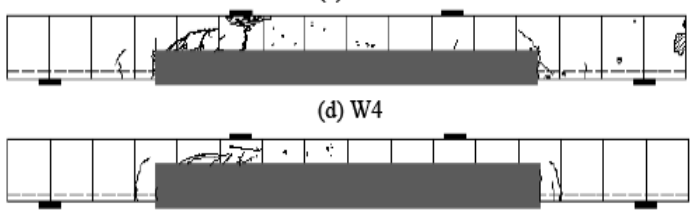

(e) W5

Fig. 6. Failure modes and Crack propagations

\section{CONCLUSION}

This study investigates strengthening effect of CFRP width on structural behaviors of RC beams. From experiments, load-deflections curves, interfacial shear stress distributions, ductility, and failure modes are analyzed. The results show that $\mathrm{RC}$ beams strengthened with the wider width CFRPs has the higher load capacity and ductility. Also, it is recommended to have wider width of CFRPs than beam width such that CFRP sheets ends at higher level than location of reinforcing steel bars.

\section{REFERENCES}

[1] N. Utui and H. S. Kim, "Experimental method for evaluating debondin $\mathrm{g}$ strength of FRPs used for retrofitting concrete structures," Korean $S$ oc. Adv. Comp. Struc., vol. 2, no. 3, pp. 36-41, 2011

[2] E. S. Choi, N. Utui, and H. S. Kim, "Experimental and analytical inves tigations FRPs for flexural strengthening of RC beams," Composites $P$ art $B$, vol. 45 , no. 1 , pp. 248-256, 2013

[3] H. S. Kim and Y. S. Shin, "Flexural behavior of reinforced concrete (R C) beams retrofitted with hybrid fiber reinforced polymers (FRPs) und er sustaining loads," Composite Stuctures, vol. 93, pp. 802-811, 2011

[4] B. O. Mongi, B. Abdeldjelil, and S. W. Bae, "Effective bond length of FRP sheets externally bonded to concrete," International Journal of C oncrete Structures and Materials, vol. 3, no. 2, pp. 127-131, 2009

[5] L. J. Li, Y. C. Guo, F. Liu, and J. H. Bungey "An experimental and nu merical study of the effect of thickness and length of CFRP on perfor 
mance of repaired reinforced concrete beams," Construction and Build ing Materials, vol. 20, pp. 901-909, 2006

[6] H. W. Zhang and S. T. Smith, "Influence of FRP anchor fan configuration and dowel angle on anchoring FRP plates," Composite part $B$, vol. 43, pp. 3516-3527, 2012

[7] S. T. Smith and J. G. Teng, "FRP -strengthened RC beams. I : review of debonding strength models," Engineering Structures, vol. 24 , pp. $385-395,2002$

[8] M. Davood and M. S. Seyed, "Externally bonded reinforcement in grooves (EBRIG) technique to postpone debonding of FRP sheets in strengthened concrete beams," Construction and Building Materials, vol. 38, pp. 751-758, 2013

[9] N. Hakan and T. Bjom, "Testing of hybrid FRP composite beams in bending," Composites part B, Vol. 35, pp. 27-33, 2004

[10] S. Win, K. Frank K, H. Harry G., "Ductile hybrid fiber reinforced plas tic reinforcing bar for concrete structures: Design methodology," $A C I$ materials journal, vol. 95-M63, pp. 655-666, 1998

[11] J. F. Chen and J. G. Teng, "shear capacity of FRP -strengthened RC beams: FRP debonding", Construction and Building Materials, vol.17, pp. 27-41, 2003

[12] Guide for the Design and Construction of Externally Bonded FRP Systems for Strengthening Concrete Structures, ACI 440.2R-02, Famington Hills, MI, USA 2002

[13] M. M. A. Kadhim, "Effect of CFRP sheet length on the behavior of HSC continuous Beam," Journal of Thermoplastic Composite Materials, pp. 1-12, 2011

[14] B. Gao, J. K. Kim, and C. K. Y. Leung, "Effect of tapered FRP sheets on interlaminar fracture behavior of FRP concrete interface," Composites Part A, vol. 37, no. 10, pp. $1605-1612,2006$

[15] F. Bencardino, G. Spadea, and R. N. Swamy, "Strength and ductility of reinforced concrete beams externally reinforced with carbon fiber fabric," ACI materials journal, vol. 99-S18, pp. 163-171, 2002
[16] S. F. Brena and B. M. Marcri, "Effect of carbon-fiber-reinforce polymer laminate configuration on the behavior of strengthened reinforced concrete beams," Journal of composites for construction, vol. 8, pp. 229-240, 2004

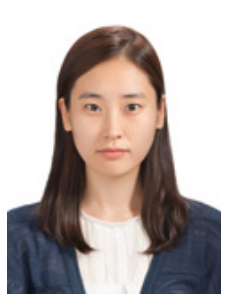

Naeun Kim is with the Architectural Engineering Department, Ewha Womans University, Seoul, South Korea.

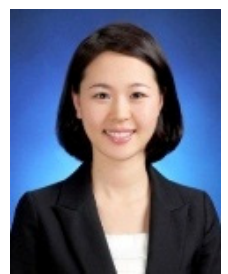

Yeong-Hee Kim is with the Architectural Engineering Department, Ewha Womans University, Seoul, South Korea.

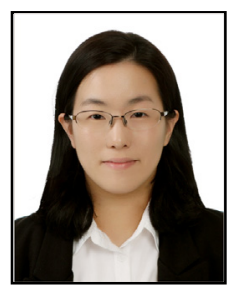

Hee Sun Kim is with the Architectural Engineering Department, Ewha Womans University, Seoul, South Korea. 